\title{
Alban Bensa, Ethnologie et architecture. Le Centre culturel Tjibaou, une réalisation de Renzo Piano
} 2000, Paris, Adam Biro, 207 p.

\section{Adriano Favole}

\section{OpenEdition}

\section{Journals}

Édition électronique

URL : http://journals.openedition.org/jso/1734

DOI : $10.4000 /$ jso. 1734

ISSN : $1760-7256$

\section{Éditeur}

Société des océanistes

Édition imprimée

Date de publication : 1 juin 2001

Pagination : 91-92

ISSN : 0300-953x

Référence électronique

Adriano Favole, "Alban Bensa, Ethnologie et architecture. Le Centre culturel Tjibaou, une réalisation de Renzo Piano », Journal de la Société des Océanistes [En ligne], 112 | Année 2001-1, mis en ligne le 28 mai 2008, consulté le 24 septembre 2020. URL : http://journals.openedition.org/jso/1734 ; DOI : https:// doi.org/10.4000/jso.1734 


\section{COMPTES RENDUS}

\author{
Alban Bensa, 2000. Ethnologie et architecture. Le Cen- \\ tre culturel Tjibaou, une réalisation de Renzo Piano, \\ Paris, Adam Biro, 207 p.
}

\section{Dialogues entre une ethnologie impliquée, une architecture 'douce' et une société ouverte.}

Dans la conclusion de son compte rendu de $L a$ présence kanak, texte recueillant les interviews, les discours, les essais de Jean-Marie Tjibaou, James Clifford observait : «On se demande comment cette 'présence kanak' sera mémorisée dans une imposante structure —un musée ? - qui va ouvrir ses portes à Nouméa : le Centre culturel Jean-Marie Tjibaou » (1998 p. 228). Avec Ethnologie et architecture, Alban Bensa donne une réponse ample et détaillée à cette question. Les deux premiers chapitres du livre parcourent quelques étapes historiques de la difficile rencontre entre Français et Kanaks (se concentrant en particulier sur les événements qui ont conduit à la 'reconnaissance culturelle' de ces derniers) et retracent les différentes phases du projet et de la construction du Centre culturel Tjibaou, inauguré en mai 1998 sur la presqu'île de Tina, à Nouméa. Du chapitre III au chapitre VI, l'auteur présente l'organisation des espaces et la structure interne du Centre : le site et l'allée centrale, les cases, le 'chemin kanak' et l'aire coutumière. Les chapitres VIII et IX sont consacrés aux objets anciens de l'art kanak, à la place qui leur est réservée au Centre, aux œuvres d'art contemporaines qui y sont exposées ainsi qu'au rôle des arts de la performance. Dans le reste du livre, Bensa réfléchit sur les choix de Renzo Piano - le célèbre architecte italien auteur du projet, avec Bensa lui-même et l'ADCK (Agence pour le développement de la culture kanak) (chap. IX) - et sur la fécondité du dialogue entre ethnologie et architecture (chap. X). Le livre s'achève sur une interview de Bensa et de Piano réalisée par Stéphane Deligeorges pour France Culture, à l'occasion de l'inauguration du Centre.

Écrit dans un style clair destiné à un public non spécialiste, Ethnologie et architecture s'enrichit d'un appareil iconographique : les images en couleur du Centre et de la Nouvelle-Calédonie alternent avec des plans, des maquettes, des détails du projet et avec des photos d'époque, accompagnant le lecteur tout au long du parcours narratif. Le choix d'un langage non spécialiste répond aux exigences d'une œuvre interdisciplinaire qui évolue entre l'ethnologie, l'architecture et la muséographie aussi bien qu'à celles, comme le rappelle Bensa lui-même, d'une « ethnologie impliquée » qui l'a conduit à « franchir la frontière entre sciences sociales et politique. À quoi bon des sciences sociales si elles ne sont pas aussi en mesure de mettre leurs outils et leurs résultats au service de transformations sociales nécessaires »? (p. 174). Appelé par Renzo Piano à faire partie de son équipe de travail, Bensa a participé personnellement à la formulation du projet et à la réalisation du Centre: son livre naît ainsi d'un dialogue serré entre un ethnologue « impliqué » spécialiste de la région, un architecte à la recherche d'une «traditionalité explicitement moderne» ( $\mathrm{p}$. 166), partisan d'une architecture « douce » (p. 169) en mesure de s'acclimater à l'environment naturel et humain, et un groupe $d$ ' 'indigènes' kanak qui, dans le sillage de la pensée politique de leur leader défunt Tjibaou, veulent construire une société ouverte, évitant toute forme de repli ethnique.

Le Centre et le livre de Bensa qui le raconte sont donc des créatures hybrides qui sacrifient l'identité (ethnique ou disciplinaire) sur l'autel du dialogue, des connexions et des métamorphoses. L'ethnologue impliqué dans le projet est présenté comme celui qui libère la tradition «des griffes du passé sans pour autant tout oublier » (p. 39), évitant les écueils de la réification et de l'essentialisme; l'architecte sélectionne quelques traits marquants de l'architecture locale (l'organisation du village kanak le long d'une allée centrale, la verticalité des cases traditionnelles, l'immersion de l'habitat humain dans le milieu naturel) pour les transformer et les adapter à des matériaux technologiquement sophistiqués, évitant les risques de l'exotisme, du kitsch, du pittoresque ; enfin les Kanaks de l'ADCK (citons en particulier Octave Togna, MarieClaude Tjibaou et Emmanuel Kasarhérou) sont engagés à réaliser dans le Centre une synthèse entre modernité et tradition, oscillant entre l'exigence de tracer une 'présence' culturelle (et politique) forte et la volonté de tisser des liens avec les autres communautés des îles du Pacifique ainsi qu'avec les autres populations présentes sur le sol calédonien.

Les thèses fortes du livre de Bensa et les messages véhiculés par le Centre sont à bien y regarder étroitement liés aux idées 'prophétiques', profondément innovatrices, de Jean-Marie Tjibaou : le refus d'une conception statique de l'authenticité et une vision que nous pourrions définir 'existentialiste' de l'être humain ; la définition dynamique de l'identité et de la tradition (« l'identité est devant nous ») ; la recherche 
de l'universalité de la culture et des valeurs sur laquelle elle se fonde aux dépens du particularisme ethnique.

$\mathrm{Au}$ Centre qui porte son nom, ces idées de Tjibaou se reflètent dans l'importance accordée à l'art contemporain du Pacifique et dans la correspondante 'désacralisation' des objets d'art anciens; dans l'ample espace réservé à la création artistique et aux arts de la performance ; dans un projet architectural qui représente la culture kanak comme un chantier aux formes inachevées, une « mémoire d'avenir » (p. 169), comme dit l'oxymore forgé par Piano lui-même. Le Centre donne corps aux réflexions du leader kanak tragiquement disparu en 1989: le nom de Centre culturel Tjibaou est de ce point de vue tout autre chose qu'une simple 'dédicace': Le Centre dans son ensemble, bien plus que la statue du leader qui lui fait face, rend l'image complexe, dynamique et 'métisse' de JeanMarie Tjibaou. Et c'est au Centre et à l'importance qu'il a acquise bien au-delà des frontières calédoniennes que les Kanaks ont confié la tâche d'effectuer le « branchement » (pour citer la métaphore informatique chère à Jean-Loup Amselle, 2001) entre leur culture et une modernité qui jusqu'à aujourd'hui les avait refusés.

Enfin, à partir des thèses de Jean-Marie Tjibaou qu'il a contribué à faire connaître en France et ailleurs, Bensa parvient à une réflexion sur la nature de la pensée anthropologique. Loin d'être un savoir mimétique qui se limite à représenter les cultures, l'anthropologie apparaît plutôt dans son analyse comme une activité 'poiétique', semblable en cela à l'architecture : « La conjonction de l'ethnologie et de l'architecture met en évidence cette dimension créatrice de l'expertise anthropologique » (p. 187). L'anthropologie construit les cultures dans la mesure où elle les rend objectives, pensables; il s'agit d'une activité créatrice appelée non pas à reconstruire un passé immuable mais à «restituer» (p. 187) les sociétés dans leur dimension ouverte et changeante.

\section{RÉFÉRENCES CITÉES}

Amselle, Jean-Loup, 2001. Branchements. Anthropologie de l'universalité des cultures, Paris, Flammarion.

Clifford, James, 1998. Our identity is ahead of us, L'Homme, 145, pp. 225-228.

Tübaou, Jean-Marie, 1996. La présence kanak, Édition établie et présentée par A. Bensa et É. Wittersheim, Paris, Odile Jacob.

Adriano Favole

Université de Turin (favole.bessone@isiline.it)
William F. S. MiLEs, 1988. Bridging Mental Boundaries in a Postcolonial Microcosm. Identity and Development in Vanuatu, Hawaii, University of Hawaii Press, xxiv +271 p., index.

Cet ouvrage est une synthèse dense, riche et très actuelle sur l'ex-condominium des NouvellesHébrides. Peu d'auteurs en effet se sont intéressés récemment aux questions de politique nationale au Vanuatu ${ }^{1}$. Dans l'introduction, l'auteur (professeur de science politique aux États-Unis et auteur de plusieurs ouvrages sur les colonies ou ex-colonies francophones d'Amérique et d'Afrique), explicite la notion de « boundary » (limite, frontière), qui sous-tend tout l'ouvrage, en même temps qu'il nous fournit un résumé géographique, historique et politique sur l'archipel. Le premier chapitre raconte l'histoire du condominium et présente les « frontières mentales » et les rivalités qu'il a créées et qui perdurent aujourd'hui. William F. S. Miles y introduit le terme « condocolonialisme », notion propre au cas du Vanuatu et qui le distingue des modes classiques de colonisation qui furent pratiquées ailleurs dans le Pacifique et à travers le monde colonial. Les chapitres 2 et 3 sont consacrés aux frontières mentales créées respectivement par le nationalisme et par la religion. Le $4^{\mathrm{e}}$ chapitre étudie la question linguistique, source éternelle de division, et le $5^{\mathrm{e}}$ aborde une série de domaines potentiellement créateurs de nouvelles frontières : le territoire, le rapport au temps, la loi, l'économie, les relations entre les sexes et entre les différentes communautés du pays... Le dernier chapitre enfin prend un peu de recul et tente de resituer le Vanuatu dans son environnement régional océanien, et plus largement dans les processus de globalisation.

Comme le dit justement Kirk Huffmann (ancien directeur du Centre culturel du Vanuatu et fin connaisseur du pays) en avant-propos, l'ouvrage de Miles a l'immense mérite de pouvoir familiariser un lecteur non averti à la vie politique et sociale d'un pays peu connu. Pour les jeunes chercheurs travaillant sur le Vanuatu ${ }^{2}$, il constituera donc un document d'autant plus utile que n'étant pas spécialiste du Pacifique, l'auteur apporte un regard neuf et sans a priori sur un certain nombre de dossiers. Il en est ainsi des réflexions sur les appartenances et les identités multiples revendiquées par les ni-Vanuatu (p. 62), sur le renforcement de l'identité insulaire depuis l'indépendance du fait des migrations vers la ville (p. 78) ou de l'acuité de ses observations sur les différences perçues, dans l'hebdomadaire officiel (le Vanuatu Weekly/Hebdomadaire publié dans les trois langues du pays : le bislama, le français et l'anglais), entre deux versions d'un même

1. Voir cependant le foisonnant ouvrage coordonné par Howard van Trease : La politique mélanésienne : stael blong Vanuatu (Suva, University of the South Pacific Press, et Christchurch, McMillan Brown Center for Pacific Studies, 1995), en grande partie écrit par des auteurs ni-Vanuatu.

2. Le pays fut durant près de dix ans interdit aux chercheurs occidentaux, et l'on doit beaucoup à Ralph Regenvanu pour la politique culturelle et de recherche qu'il a mise en place depuis le milieu des années 1990. 